\section{Aboriginal relations strained by theft of dinosaur footprints}

Sydney. Thieves have sawn rare fossilized dinosaur footprints out of rocks in Western Australia, angering palaeontologists who had been hoping to identify the animals possibly stegosaurs - that left the marks.

The theft has caused bitterness in the local Rubibi Aboriginal community, which has regarded the area as sacred for generations. The site is on a foreshore near Broome in the north of the state. The fossilbearing rocks were first examined by scientists in 1991, following the promotion by the Western Australian Museum in Perth of a public "great dinosaur hunt".

The area is rich in footprints of brontosaurs, other herbivores and predator dinosaurs. But Tony Thulborn, a palaeontologist at the University of Queensland, says the stolen footprints were "different and very rare". The prints of five-fingered hands are about $20 \mathrm{~cm}$ wide and somewhat shorter in length; the three-toed hind feet are $20 \mathrm{~cm}$ long and narrower in width.

Thulborn says the early Cretaceous sediment in the region is thought to be between 114 million and 120 million years old, and reveals what he describes as a "treasure trove" of diverse fauna walking on a forest floor. Confirmation that stegosaurs lived in Australia would reinforce the inclusion of the Australian continent as part of the southern supercontinent of Gondwana at that time.

But Thulborn challenges claims that the fossil footprints are sufficiently distinct for unambiguous identification as stegosaurs, which would give them historical precedence over other unpublished claims, mainly from North America. Given the limited studies so far, he says that he can categorize the animals that left the prints only as thyreophorans, a group of armoured, herbivorous dinosaurs that includes stegosaurs and ankylosaurs.

Following the 'hunt', mostly by amateurs, Thulborn says it took five years for him to establish confidence among the Aborigines to gain access to the site for detailed, professional studies of the footprints. He claims that the theft of the specimens is "not scientifically devastating" as casts and photos had been taken. But he adds that "the real loss is in understanding of our work among the local community which holds that sacred sites should be seen only by initiated males".

Publication of pictures in the media has not helped to capture the thieves. It seems unlikely that professional collectors were involved, as the museum and black markets are profitable more for large skeletons than for footprints, which are not easy to see. Peter Pockley

\title{
Max Planck institutes 'could still be saved from closure'
}

Munich. At least one of four research institutes run by Germany's Max Planck Society (MPS) that were unexpectedly earmarked for closure earlier this month could be saved, according to Hubert Markl, president of the society.

But this will require the government to modify its so-called 'federal consolidation programme' under which all publicly funded institutes are to shed 2 per cent of their workforce annually to the end of the decade (see Nature 383, 566; 1996).

$$
\text { According to }
$$

Markl, Jürgen Markl: fighting cuts.

Rüttgers, the fed-

IMAGE
UNAVAILABLE
FOR
COPYRIGHT
REASONS

eral research minister, has told him informally that the programme will be extended beyond 1998 - its approved lifespan - to at least 2000, and that the Max Planck Society will not be exempt. Markl says this is why it became necessary to announce the closures. But he says that the best chance of the institutes' survival is for politicians to be sufficiently moved by the seriousness of the situation to exempt the society as a whole from the federal consolidation programme.

The MPS has long been warning that closures were likely in the west of the country if its budgetary squeeze continued. Markl

says that the principle had been widely acknowledged. But now that it has become a reality, and he has thrown the names of four west German institutes into the arena, reactions have been hostile. "I expected some president-bashing," he says.

The four institutes destined for closure - two in biology, one in history and one in space science - are asking their respective regional (Länder) governments and scientific communities to support their attempts to stay open. The Institute for Aeronomy in Lindau has already attracted international support, largely because of its involvement in international planetary missions (see below). The institutes will have time to consider their strategy, as the decisionmaking procedures are relatively slow.

If the society is not exempted from the federal consolidation programme, the closure of the four institutes will not be the end of the story, as the resulting staff reduction will total only about half of that required. Markl has asked each of the society's three sections - biology, physical sciences and humanities - to suggest six departments for closure, cutting an additional 250 posts.

Axel Korth, a spokesman for the Institute for Aeronomy, says that some researchers are hoping that the MPS will decide to close more departments, to save whole institutes. But this is thought unlikely. All final closure decisions will be taken during next year.

Alison Abbott

\section{Plans cast cloud over Rosetta mission}

Munich. Concern is growing about the fate of the European Space Agency (ESA) Rosetta mission to the comet Wirtanen, due to be launched in 2003 , following the announcement that the Max Planck Institute for Aeronomy at Lindau, Germany, could be closed within the next few years (see above).

The institute is the base for two of the mission's principal investigators, who are developing a microwave spectrometer and Rosetta's imaging system, called Osiris. The Lindau institute is also principal developer for Rosetta's lander.

The uncertainty is causing substantial concern, says Marcello Coradini, ESA pokesman for Solar System sciences. The payloads will be finally approved next February. But the Lindau scientists will find it hard to attract commitments of funding from national research agencies while their institute's own existence is in doubt, he says.

Hans Balsiger, a Solar System scien- tist from the University of Bern in Switzerland, calls threatened closure of the institute "totally irresponsible". The Max Planck Society has not considered the international dimension, he says. Balsiger shares with the Lindau institute responsibility for one of Rosetta's instruments, and is also chairman of ESA's science programme committee.

Hubert Markl, president of the society, says that current commitments to Rosetta projects will be fulfilled. One reason for selecting the Lindau institute for closure, he says, is that space research is primarily a federal responsibility.

Markl plans to discuss a possible takeover of the institute by DLR, the National Air and Space Research Centre, with DLR's director general, Walter Kröll, in December. But scientists at Lindau view the possible takeover with alarm, as the centre does not share its tradition of conducting basic research alongside instrument development.

A. A. 